\title{
Hydrothermal oxidation of organochlorines
}

\author{
S. Bachir ${ }^{1}$, M. Ambrosio*,1, V. Federici² and H. Barnier ${ }^{2}$ \\ ${ }^{1}$ Université de Provence, 3 place Victor Hugo, Case 29, 13331 Marseille, France \\ ${ }^{2}$ CEA - SEP/LPTE Cadarache, 13108 St-Paul-Lez-Durance, France
}

\begin{abstract}
The hydrothermal oxidation of four organochlorines (perchloroethylene, 1,1,1 trichloroethane, trichloroethylene and dichloromethane) was studied. This study aims at determining the influence of various parameters and the optimal conditions for obtaining the best oxidation yield in the degradation process. The factors studied were reaction temperature, initial substrate concentration, reaction time, agitation speed and volume of the solution in the reactor vessel. The tests were conducted following the methodology of experimental design. The results obtained show that these compounds are degraded rather easily in the working conditions. The degradation efficiency can reach $98 \%$ of the total organic carbon and $99.9 \%$ of the initial substrate concentration. The temperature and the initial substrate concentration are the most influential factors on the oxidation process. The reaction time and the volume of the solution have a less interesting influence on the degradation yield in the experimental areas. Formic acid and methanol are the byproducts found in the final effluents. Their concentrations decrease considerably when the reaction temperature is higher. The chlorine is found essentially in the $\mathrm{Cl}^{-}$form.
\end{abstract}

Key words. Organochlorines — water — oxidation — organic carbon — chlorine — optimization — experimental design.

\section{Abbreviations}

$\triangle T O C$ Yield of degradation according to the total organic carbon in solution.

$T O C_{\mathrm{f}}$ Total organic carbon in solution at the end of the reaction.

$T O C_{\text {in }}$ Total organic carbon in solution at the initial state.

$\Delta S \quad$ Yield of degradation according to the initial substrate concentration in solution.

$[S] \quad$ substrate concentration.

$X_{1} \quad$ Temperature $\left({ }^{\circ} \mathrm{C}\right)$.

$X_{2} \quad$ Reaction time (minutes).

$X_{3} \quad$ Volume of the solution in the reactor $(\mathrm{mL})$.

$X_{4} \quad$ Initial substrate concentration $\left(\mathrm{g} \mathrm{L}^{-1}\right)$.

$X_{5} \quad$ Agitation speed (revolution per minute).

$\sigma \quad$ estimated significance level.

PCE Perchloroethylene.

TCE Trichloroethylene.

TCA 1,1,1 Trichloroethane.

DCM Dichloromethane.

\section{Introduction}

The hydrothermal oxidation technique is an industrial wastewater process treatment that consists in literally burning in water all the organic matter to transform it into mineral products. This process presents three essential advantages [1,2]:

- There is a fast destruction of the wastes and byproducts created at relatively low reaction temperatures what permits, on one hand to considerably decrease material corrosion and on the other hand, to avoid the formation of dioxins and other polluting gases $\left(\mathrm{NO}_{x}, \mathrm{SO}_{2}\right)$; in this way the gaseous effluents obtained are cleaner than those produced by incineration.

- It also permits an energy recovery and in some cases, the valorization of the by products.
- The operating costs of the installation are lower compared to those of the incineration process.

The hydrothermal oxidation technique has been the object of many industrial applications, mainly in the treatment of sewage sludge. Many tests on different type of wastes have been reported in several publications [3-11].

A better optimization of the degradation efficiency needs the effective knowledge of the different factors influencing the reaction, their respective levels of influence as well as the control of the degradation mechanisms. From this perspective, the study of model compounds is essential to make predictions on real wastes. To this end, Hao O.J. [12] and Shende [13] obtained interesting results respectively on the nitrotoluene sulfonic acid, and the antraquinone and phtalocyanine.

Although many results on several pure compounds have been reported, little is kown about organochlorines that nevertheless, are used in a lot of industrial processes [14-16]. These compounds are used as solvent in many processes and also for removal of grease marks on metals. Therefore, they pose a real environmental safeguard problem.

The present paper focuses on the application of the hydrothermal oxidation technique in the degradation of four organochlorines, which are perchloroethylene, 1,1,1 trichloroethane, trichloroethylene and dichloromethane. The study was conducted following the methodology of experimental design. Indeed, this methodology permits to obtain the necessary information with the best possible quality while minimizing the number of experiences [17-19]. The difference with the classic method is due to the fact that levels of both parameters are varied in each experience in a programmed and controlled way. Homogeneous and heterogeneous catalysis tests were made to estimate the yield improvement obtained by using them. 


\section{Original articles}

\section{Materials and methods}

\section{Equipment}

Tests were carried out in the installation schematized in scheme 1. This installation includes:

- A 500-mL autoclave equipped with an agitator and thermocouple. The autoclave is placed in an electrical oven and kept hermetically shut by twelve screws.

- Liquid and gas sample lines equipped with a cooling system and a condensation pot.

- Gas inlet system composed of two lines: the oxidizing mixture $\mathrm{N}_{2} / \mathrm{O}_{2}(50 \% / 50 \%)$ line and the low nitrogen pressure line to purge the reactor before the beginning of the experiment.

- A safety system with an electrovalve and a disjointing disc. The opening of the electrovalve that permits the disposal of the system is activated when the pressure or the temperature reaches the threshold fixed by the operator.

\section{Experimental protocol}

A known volume of the substrate solution was introduced into the reactor that is then closed hermetically. Nitrogen was bubbled into the autoclave to drive off air. After programming the oven, the agitation was initiated and the reactor was heated till the desired reaction temperature. Once this temperature was reached, the oxidant was fed into the vessel in large excess in relation to the stoichiometry of the complete combustion reaction.

It assumes that the reaction time starts from the introduction of oxygen. In order not to disturb the reaction, no liquid or gaseous samples were withdrawn during the experiment. At the end of the operation, the reactor is rapidly cooled down and the liquid effluent is recovered for physicochemical analysis.

\section{Analytical techniques}

The following methods were used to analyze the final effluent resulting from the substrate oxidation:

- A PROTOC 2000 analyzer was used to determine the total organic carbon (TOC). The principle of the analysis is based on an oxidation by sodium peroxodisulphite catalyzed by UV rays and infrared detection of $\mathrm{CO}_{2}$ formed. An integrated system allows the calculation of the TOC and total carbon concentrations. The calibration is conducted with a potassium hydrogenophtalate solution.

- Chloride ions $\left(\mathrm{Cl}^{-}\right)$and formic acid were determined via a DIONEX DX 100 chromatograph associating an ion exchange with a conductimetric detection. The separation column was AS 4 type constituted by a quaternary ammonium resin in hydroxyl form. The anion elution is done by mixing sodium carbonate $\left(1.7 \mathrm{mmol} \mathrm{L}^{-1}\right)$ and sodium hydrogenocarbonate $\left(1.8 \mathrm{mmol} \mathrm{L}^{-1}\right)$ solution.

- The separation and determination of organochlorines and other organic components in the final effluent were carried out on a Hewlett Packard 5890 series 2 chromatograph with a CP-SIL-5CB fused Silica WCOT capillary column (Film 5 microns, internal diameter of $0.32 \mathrm{~mm}$ and a $25 \mathrm{~m}$ of length) and a flame ionization detector (FID). The concentrations of the compounds were estimated vs. a calibration process by the chemstation computer program.

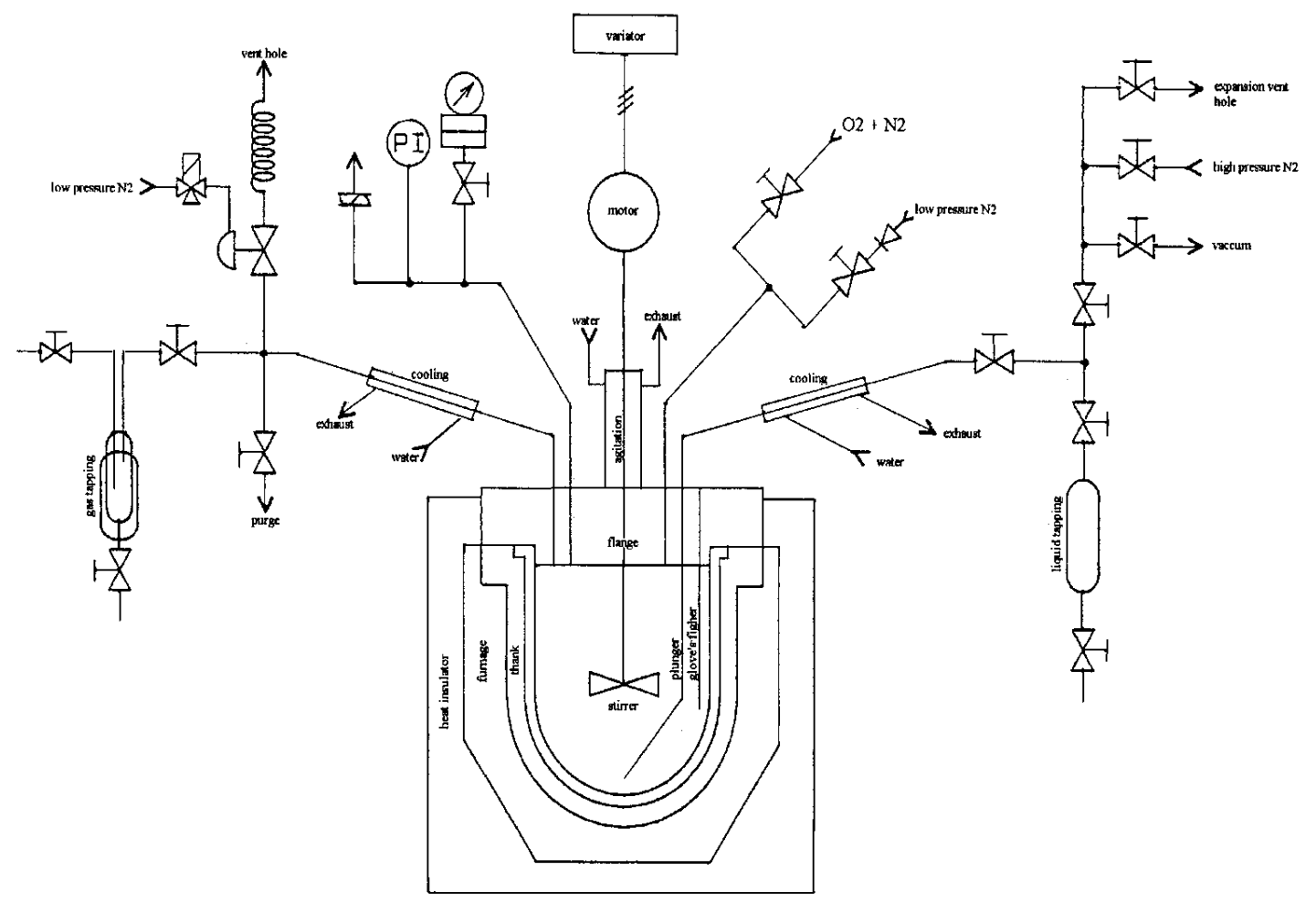

Scheme 1. Experimental setup. 


\section{Results and discussion}

The compounds studied present some common characteristics. They are mostly insoluble in water; their respective volumetric densities are superior to one. Once in the reactor, these compounds are dispersed in the water due to the agitation of the system. The oxidation reaction takes place essentially in the liquid phase. No liquid or gaseous samples are withdrawn before cooling the reactor to avoid any disturbance of the reaction. A known concentration of sodium carbonate is introduced into the initial solution to keep the $\mathrm{pH}$ of the reaction medium close to 7 and to limit the corrosion due to the formation of mineral acids.

The evolution of the reaction was followed by characterizing and comparing the initial and final states of the system. In the initial state, the liquid phase contained sodium carbonate, substrate solution and in the gaseous phase there was only nitrogen. In the final state the liquid phase contained oxidation byproducts and the gaseous phase was composed of $\mathrm{N}_{2}, \mathrm{O}_{2}, \mathrm{CO}_{2}$, and possibly gaseous oxidation products.

The degradation yield is calculated by determining the total organic carbon in the initial and final states in the liquid phase using the following expression:

$$
\Delta T O C=\frac{[T O C]_{\text {in }}-[T O C]_{\mathrm{f}}}{[T O C]_{\mathrm{f}}} \times 100
$$

Preliminary tests showed that 1,1,1 trichloroethane and trichloroethylene are the most easily degraded compared to dichloromethane and perchloroethylene. In order to limit the number of tests, one mathematical model was developed for every substrate. A full factorial design $2^{3}$ was applied to the degradation of trichloroethane. The results of this design are later used to build a fractional factorial design $2^{4-1}$, which was applied to the degradation of PCE. For a greater precision of the modelization of the response, a second-degree model was chosen to study the degradation of dichloromethane. The uniform Dœlhert matrix is well fitted for the operating conditions.

\section{Degradation of 1,1,1 trichloroethane (TCA)}

The full factorial design $2^{3}$ allows to study the influence of three factors and their respective interactions: This factorial design is the simplest and most useful one. The expression $2^{3}$ means that there are three factors studied and two levels for each factor. The factors studied are the reaction temperature $\left(X_{1}\right)$, the initial trichloroethane concentration $\left(X_{2}\right)$ and the agitation speed $\left(X_{3}\right)$. The reaction time and the volume of the solution are kept constant $(30$ minutes and $250 \mathrm{~mL}$, respectively). The levels of the variables and the experimental matrix are represented in tables I and II.

The results show that $1,1,1$ trichloroéthane is easily degraded (Tab. III). The oxidation reaction gives intermediate components such as dichloromethane and in a smaller rate methanol and formic acid. The degradation yields vary greatly, which indicates that at least one of the factors studied has a remarkable influence on the experimental area.

The calculation of the main effects and their interactions (see Fig. 1) shows that the temperature is the essential factor in the degradation process. A temperature increase from $200{ }^{\circ} \mathrm{C}$ to $300{ }^{\circ} \mathrm{C}$ appreciably improves the $T O C$ efficiency
Table I. 1,1,1-Trichloroethane degradation: Factors levels and experimental area.

\begin{tabular}{lccc}
\hline Variables & Factors & \multicolumn{2}{c}{ Levels } \\
& & -1 & +1 \\
\hline$X_{1}$ & Reaction temperature & $200{ }^{\circ} \mathrm{C}$ & $300{ }^{\circ} \mathrm{C}$ \\
$X_{2}$ & Initial substrate concentration & $5 \mathrm{~g} \mathrm{~L}^{-1}$ & $30 \mathrm{~g} \mathrm{~L}^{-1}$ \\
$X_{3}$ & Agitation speed & $500 \mathrm{rpm}$ & $1500 \mathrm{rpm}$ \\
\hline
\end{tabular}

Table II. 1,1,1-Trichloroethane degradation: The full factorial experience matrix $2^{3}$.

\begin{tabular}{lccc}
\hline$N^{\circ}$ trials & Factor 1 & Factor 2 & Factor 3 \\
\hline 1 & - & - & - \\
2 & + & - & - \\
3 & - & + & - \\
4 & + & + & - \\
5 & - & - & + \\
6 & + & - & + \\
7 & - & + & + \\
8 & + & + & + \\
\hline
\end{tabular}

Table III. 1,1,1-Trichloroethane degradation: Experimentation plan and responses.

\begin{tabular}{lcccc}
\hline$N^{\circ}$ trials & \multicolumn{3}{c}{ Variables } & Responses \\
& $U_{1}\left({ }^{\circ} \mathrm{C}\right)$ & $U_{2}\left(\mathrm{gL} \mathrm{L}^{-1}\right)$ & $U_{3}(\mathrm{rpm})$ & $\Delta$ COT \\
\hline 1 & 200 & 5 & 500 & $62 \%$ \\
2 & 300 & 5 & 500 & $88 \%$ \\
3 & 200 & 30 & 500 & $25 \%$ \\
4 & 300 & 30 & 500 & $92 \%$ \\
5 & 200 & 5 & 1500 & $69 \%$ \\
6 & 300 & 5 & 1500 & $79 \%$ \\
7 & 200 & 30 & 1500 & $27 \%$ \\
8 & 300 & 30 & 1500 & $83 \%$ \\
\hline
\end{tabular}

to $40 \%$. The initial concentration of the substrate causes the reduction of the global oxidation yield. This diminution is on an average of $20 \%$ for a variation of $5 \mathrm{~g} \mathrm{~L}^{-1}$ to $30 \mathrm{~g} \mathrm{~L}^{-1}$. The effect of the agitation speed is smaller compared to the one of the two first factors; this means that the increase of the agitation speed does not improve the TOC yield.

The most significant interaction effect is $E_{12}$ (the interaction between temperature and the initial substrate concentration).

\section{Degradation of the perchloroethylene (PCE)}

The fractional factorial design $2^{4-1}$ allow to study four factors, which are temperature $\left(X_{1}\right)$, reaction time $\left(X_{2}\right)$, volume of the solution introduced into the reactor $\left(X_{3}\right)$ and initial perchloroethylene concentration $\left(X_{4}\right)$. This design allows to considerably decrease the number of tests in comparison to the full design. This implies that the estimations of the investigated effects are aliased.

The experience matrix is based on a full design $2^{3}$. The first three columns allow to study 3 factors. A fourth factor can be studied on one of the signs of interactions: 12, 13, 


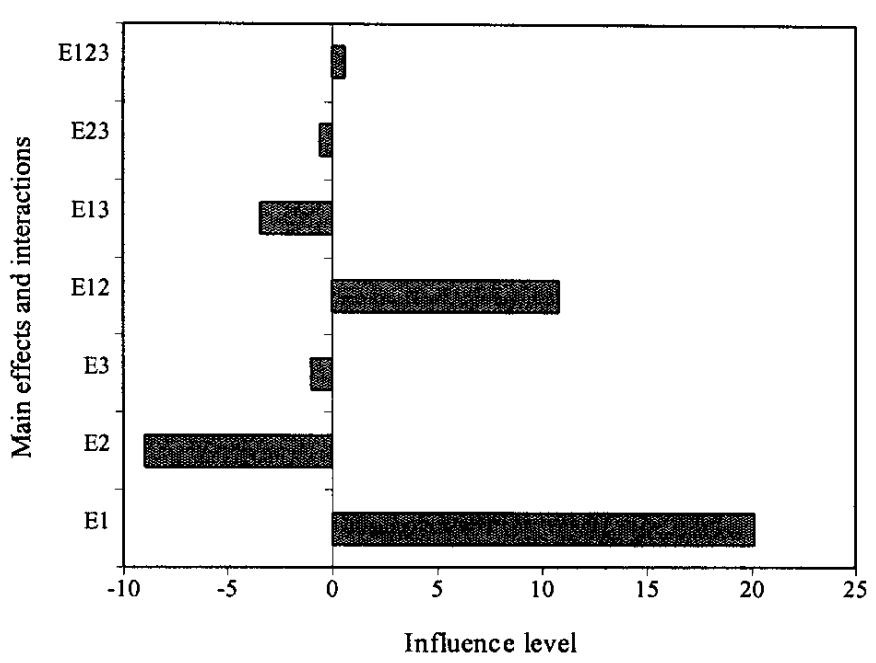

Fig. 1. Results of the factorial plan $2^{3}$ for 1,1,1-trichloroethane hydrothermal oxidation. $E_{1}=$ Main effect of temperature; $E_{2}=$ Main effect of substrate concentration; $E_{3}=$ Main effect of agitation speed; $E_{12}=$ interaction between temperature and substrate concentration; $E_{13}=$ interaction between temperature and agitation speed; $E_{23}=$ interaction between substrate concentration and agitation speed; $E_{123}=$ interactions between temperature, substrate concentration and agitation speed.

23, and 123. In the present study, we chose the interaction column 123. The levels of variables and the experimentation plan are represented respectively in tables IV and V. The generator of aliases is $I=1234$. This generator allows to calculate the manner whose effects are aliased with interactions. These aliases are the following:

$L_{1}=E_{1}+E_{234}=$ main effect of temperature plus interaction between reaction time, volume of solution and substrate concentration;

$L_{2}=E_{2}+E_{134}=$ main effect of reaction time plus interaction between temperature, volume of solution and substrate concentration;

$L_{3}=E_{3}+E_{124}=$ main effect of volume of solution plus interaction between temperature, reaction time and substrate concentration;

$L_{4}=E_{4}+E_{123}=$ main effect of substrate concentration plus interaction between temperature, reaction time and volume of solution;

$L_{12}=E_{12}+E_{34}=$ interaction between temperature and reaction time plus interaction between volume of solution and substrate concentration;

$L_{24}=L_{13}=E_{13}+E_{24}=$ interaction between temperature and volume of solution plus interaction between reaction time and substrate concentration;

$L_{23}=L_{14}=E_{14}+E_{23}=$ interaction between temperature and substrate concentration plus interaction between reaction time and volume of solution.

The degradation by-products are hydrochloric acid, $\mathrm{CO}_{2}$ and other organic intermediates such as formic acid and methanol, which are detected in a low concentrations. The total organic carbon in the final effluent is directly depen-
Table IV. Perchloroethylene degradation: Factors and experimental areas.

\begin{tabular}{lccc}
\hline Variables & Factors & $\begin{array}{c}\text { lower level } \\
-1\end{array}$ & $\begin{array}{c}\text { upper level } \\
+1\end{array}$ \\
\hline$X_{1}$ & Temperature & $200{ }^{\circ} \mathrm{C}$ & $300{ }^{\circ} \mathrm{C}$ \\
$X_{2}$ & Reaction time & $30 \mathrm{~min}$ & $60 \mathrm{~min}$ \\
$X_{3}$ & Volume of the solution in the reactor & $150 \mathrm{~mL}$ & $250 \mathrm{~mL}$ \\
$X_{4}$ & Initial substrate concentration & $5 \mathrm{~g} \mathrm{~L}^{-1}$ & $30 \mathrm{~g} \mathrm{~L}^{-1}$ \\
\hline
\end{tabular}

Table V. Perchloroethylene degradation: Experimentation plan.

\begin{tabular}{ccccccc}
\hline$N^{\circ}$ trials & \multicolumn{7}{c}{ Variables } & & Responses \\
& $U_{1}\left({ }^{\circ} \mathrm{C}\right)$ & $U_{2}(\min )$ & $U_{3}(m L)$ & $U_{4}\left(g L^{-1}\right)$ & $\Delta P C E$ & $\Delta C O T$ \\
\hline 1 & 200 & 30 & 150 & 5 & $88 \%$ & $69 \%$ \\
2 & 300 & 30 & 150 & 30 & $67 \%$ & $65 \%$ \\
3 & 200 & 60 & 150 & 30 & $56 \%$ & $53 \%$ \\
4 & 300 & 60 & 150 & 5 & $99 \%$ & $93 \%$ \\
5 & 200 & 30 & 250 & 30 & $63 \%$ & $58 \%$ \\
6 & 300 & 30 & 250 & 5 & $99 \%$ & $89 \%$ \\
7 & 200 & 60 & 250 & 5 & $98 \%$ & $98 \%$ \\
8 & 300 & 60 & 250 & 30 & $77 \%$ & $77 \%$ \\
\hline
\end{tabular}

dent on degradation level of perchloroethylene not de graded. The degradation yield varies between $53 \%$ and $93 \%$ of TOC according to operative conditions. The analysis of the main effects and interactions (see Fig. 2) shows that the factors $X_{1}$ (reaction temperature) and $X_{4}$ (initial substrate concentration) have a significant influence on the global degradation process. But these two factors act in just opposite direction, just as in the full design $2^{3}$ applied to TCA. Indeed, a reaction temperature increase results in the improvement of the efficiency in TOC efficiency. This improvement reaches $14 \%$ in a temperature increase from $200{ }^{\circ} \mathrm{C}$ to $300{ }^{\circ} \mathrm{C}$. On the other hand, the initial perchloroethylene concentration exerts a negative influence on this yield which decreases in an average of $20 \%$ when there is an increment in substrate concentration from the lower level $\left(5 \mathrm{~g} \mathrm{~L}^{-1}\right)$ to the upper level (30 $\mathrm{g} \mathrm{L}^{-1}$ ). The other factors (reaction time and volume of the solution in the reactor vessel) have a positive effect on the TOC yield, but with a minor intensity in absolute value than the two previous ones. The improvement due to these factors is about $8 \%$ from 30 minutes to 60 minutes and from $150 \mathrm{~mL}$ to $250 \mathrm{~mL}$, respectively. Concerning the interaction effects, they seem to have an insignificant influence on the degradation process (significance level $\sigma_{\mathrm{TOC}}=1.42$ ).

The calculation of the main effects and interactions on the perchloroethylene oxidation yield $\left(Y_{2}\right)$ shows the same trends as those of the TOC yield. The influence of the temperature is though slightly less strong than in the case of the TOC yield. The increase of the oxidation yield is approximately $10 \%$ and not $14 \%$ for the same variation of temperature. On the contrary, the initial PCE concentration becomes here more influential. This yield diminishes in an average of $30 \%$ from $5 \mathrm{~g} \mathrm{~L}^{-1}$ to $30 \mathrm{~g} \mathrm{~L}^{-1}$ of substrate concentration. The volume of the solution in the reactor vessel (variable $X_{3}$ ) has a minor effect than the two previous ones on $Y_{2}$. The reactiontime has an effect on the significance levels $\sigma_{\mathrm{PCE}}=1.05$. 


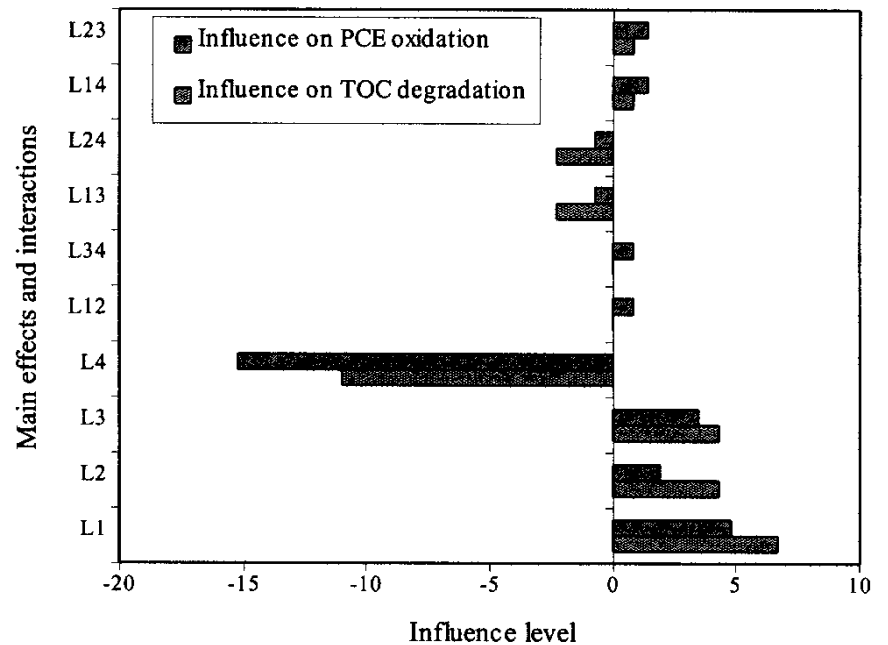

Fig. 2. Results of the fractional factorial plan $2^{4-1}$ for PCE hydrothermal oxidation.

This can be accounted for by the fact that the reaction proceeds in the first minutes of the introduction of the oxidizing mixture. Then there is a slower oxidation of the intermediate compounds formed, which produces a slight variation of the efficiency between the two levels (30 minutes and 60 minutes).

The interactions between factors seem to be not as significant as in the case of the TOC yield. In conclusion, a better oxidation efficiency of PCE is obtained at higher reaction temperatures, small substrate concentration and higher solution volumes.

The chlorine liberated during the reaction is found essentially in the $\mathrm{Cl}^{-}$ion form in the final effluent. Its concentration depends on the quantity of PCE degraded and the $\mathrm{pH}$ of the reaction medium. The hydrochloric acid is found in the gaseous phase.

\section{Degradation of the Trichloroethylene (TCE)}

The trichloroethylene oxidation was followed according to the initial substrate concentration. Tests were carried out at $300{ }^{\circ} \mathrm{C}$ for a reaction time of 30 minutes. The TCE concentrations were $5,10,20$, and $30 \mathrm{~g} \mathrm{~L}^{-1}$, respectively.

The degradation with formation of methanol whose concentration in the final effluent increases with the initial substrate concentration. Also there is formic acid production, but in a smaller proportion. Its concentration becomes significant only for higher quantities of TCE degraded. On the other hand, the reaction does not produce dichloromethane. The oxidation yield can exceed $98 \%$ of the initial substrate. The TOC yield decreases appreciably when the initial substrate concentration varies from $5 \mathrm{~g} \mathrm{~L}^{-1}$ to $30 \mathrm{~g} \mathrm{~L}^{-1}$ (see Fig. 3 ). This confirms the negative influence of the initial substrate concentration that was observed during the analysis of the factorial design applied on trichloroethane and perchloroethylene. This negative influence can be explained by the fact that the more there is substrate to degrade, the more there are organic intermediates in solution that better resist

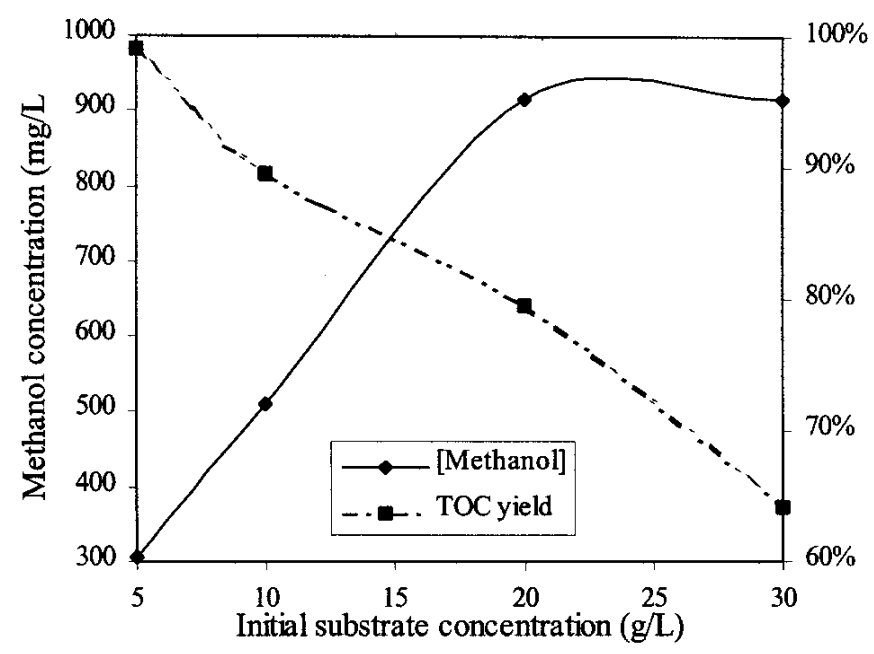

Fig. 3. Trichloroethylene degradation: Evolution yield and methanol concentration.

to the oxidation. The formation of these reaction intermediates slows down the global degradation process.

\section{Optimization of the hydrothermal oxidation}

To optimize the reaction oxidation, we chose a Dœlhert design and dichloromethane as substrate. The simplicity of its construction and the good qualities of the experience matrix [17] motivated the choice of this second-degree mathematical model. The substrate is the most soluble of the four compounds studied and it was found that it is an intermediate component in the trichloroethane degradation. The factors, the experimental area and the experimentation plan are represented respectively in tables VI and VII. The constant parameters are the volume of the solution $(250 \mathrm{~mL})$ and the pressure of the oxidizing mixture $\mathrm{N}_{2} / \mathrm{O}_{2}$ (55 bars). This oxidizing mixture pressure is more than the necessary quantities for the stoichiometric combustion according to the following reaction.

$$
\mathrm{CH}_{2} \mathrm{Cl}_{2}+\mathrm{O}_{2} \rightarrow \mathrm{CO}_{2}+2 \mathrm{HCl}
$$

The statistical processing of the results was done with the Nemrod computer program [20] leading to the following equation:

$$
\begin{aligned}
Y_{1}=70.30+ & 27.04 \times X_{1}-1.32 \times X_{2}+5.45 \times X_{3} \\
- & 4.90 \times X_{1}^{2}-9.30 \times X_{2}^{2} \\
-20.42 \times X_{3}^{2}- & 9.58 \times\left(X_{1} \times X_{2}\right)-9.90 \times\left(X_{1} \times X_{3}\right) \\
+ & 8.87 \times\left(X_{2} \times X_{3}\right)
\end{aligned}
$$

The graphical representation allows a better visualization of all the results. Figure 4 shows the factor progression in the yield maximization. We observed that the optimal path goes through a sensible increase of the temperature and a slight diminution of the substrate concentration. The 40 minutes reaction time is quite enough. A yield close to $100 \%$ can be obtained for temperature and concentration around $320{ }^{\circ} \mathrm{C}$ and $15 \mathrm{~g} \mathrm{~L}^{-1}$, respectively. The analysis of the isoresponse curves shows that the yield improvement vs. reaction temperature and reaction time is varies a lot according to the experimental area. In general, we observed a progressive narrowing of these curves at the highest temperature area 
Table VI. Dœlhert matrix: Factors and experimental areas.

\begin{tabular}{lccc}
\hline Variables & Factors & Center & Variation step \\
\hline$X_{1}$ & Reaction temperature & $280{ }^{\circ} \mathrm{C}$ & 40 \\
$X_{2}$ & Initial dichloromethane concentration & $15 \mathrm{~g} \mathrm{~L}^{-1}$ & 10.395 \\
$X_{3}$ & Reaction time & $40 \mathrm{~min}$ & 20.79 \\
\hline
\end{tabular}

Table VII. Dichloromethane degradation: Experimentation plan.

\begin{tabular}{lcccc}
\hline$N^{\circ}$ trials & $U_{1}\left({ }^{\circ} \mathrm{C}\right)$ & $U_{2}\left(\mathrm{~g} \mathrm{~L}^{-1}\right)$ & $U_{3}(\min )$ & $\left(Y_{1}\right)$ \\
\hline 1 & 320 & 15 & 40 & $96 \%$ \\
2 & 240 & 15 & 40 & $54 \%$ \\
3 & 300 & 24 & 40 & $61 \%$ \\
4 & 260 & 6 & 40 & $59 \%$ \\
5 & 300 & 6 & 40 & $87 \%$ \\
6 & 240 & 24 & 40 & $50 \%$ \\
7 & 300 & 18 & 57 & $88 \%$ \\
8 & 260 & 12 & 23 & $18 \%$ \\
9 & 300 & 12 & 23 & $76 \%$ \\
10 & 280 & 21 & 23 & $59 \%$ \\
11 & 260 & 18 & 57 & $52 \%$ \\
12 & 280 & 9 & 57 & $39 \%$ \\
13 & 280 & 9 & 57 & $70 \%$ \\
14 & 280 & 15 & 40 & $71 \%$ \\
\hline
\end{tabular}

and short reaction times. The longer the reaction time, the wider the space between the curves, which is markedly at temperatures inferior to $280{ }^{\circ} \mathrm{C}$, this is translated in a slow improvement of the degradation yield. Figures 5 and 6 illustrate the variation of the yield curves. The yield can not attain $68 \%$ for $X_{1}<0$ and $X_{2}<0$.

\section{Catalysis study}

The two catalysts tested were $\mathrm{Cu}^{2+}$ ion for the homogeneous catalysis and lanthanide oxide $\mathrm{LaCoO}_{3}$ (perovskite) for the heterogeneous catalysis. The choice of these catalysts was motivated by their relatively low cost price and their efficiency demonstrated in the degradation of some organic substances $[21,22]$. The specific surface of the oxide used is $7.7 \mathrm{~m}^{2} \mathrm{~g}^{-1}$. Tests were conducted with $1 \mathrm{~g} \mathrm{~L}^{-1}$ catalyst $\left(\mathrm{CuSO}_{4}\right.$ or $\left.\mathrm{LaCoO}_{3}\right)$ concentration.

The analysis of the results (Tab. VIII) permits to assert that the homogeneous catalysis (with the $\mathrm{CuSO}_{4}$ ) gives better results on the whole of the compounds studied, than the catalysis produced by the Lanthanide oxide. This latter has truly been efficient only on perchloroethylene for whom it improved the yield to $21 \%$ compared to the test done without the use of any catalyst. The vanadium oxide tested on dichloromethane produces an intermediate result $(76 \%$ of TOC yield). The effect of the catalysis on the formation of organic refractory intermediates and mainly methanol can not be correctly appreciated since this component is formed in the presence or absence of catalysts. Its concentration varies according to the initial substrate and the reaction temperature.

A precipitate is observed in the final effluents obtained in the tests conducted with copper sulfate. Moreover, a deposit of copper is observed on the immersed parts of the reactor
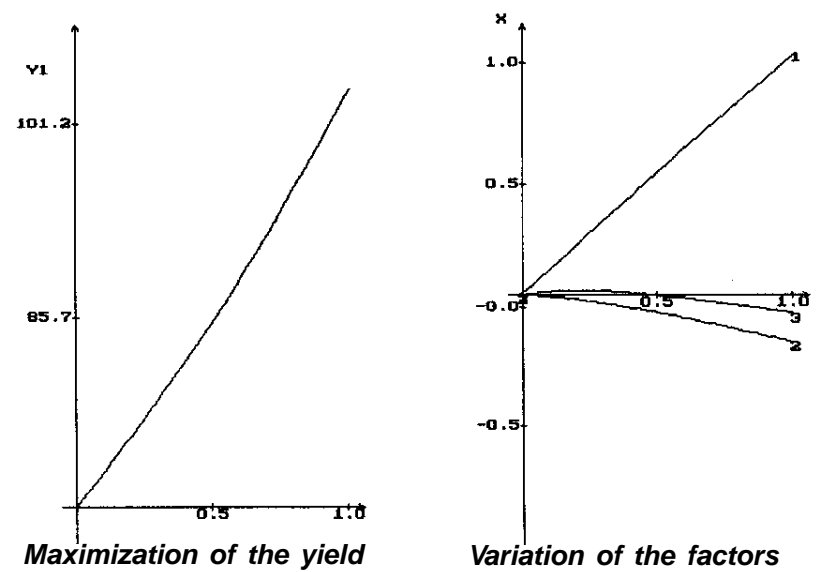

Fig. 4. Optimization of dichloromethane degradation: Optimal path study $(1=$ variation of reaction temperature; 2 = variation of substrate concentration; 3 = variation of reaction time).
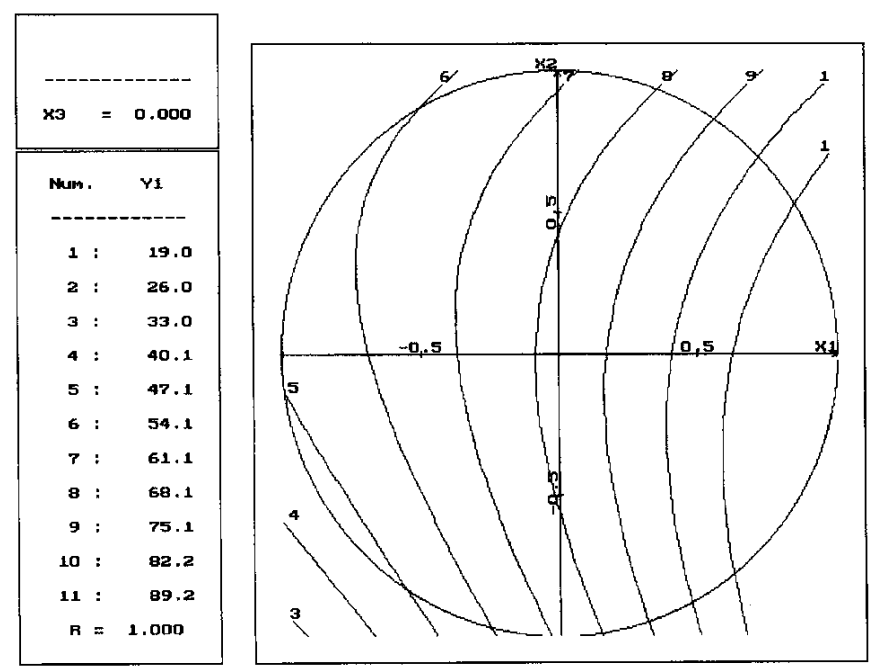

Fig. 5. Optimization of dichloromethane degradation: Variation of the degradation yield according to reaction temperature $\left(X_{1}\right)$ and initial substrate concentration $\left(X_{2}\right)$.
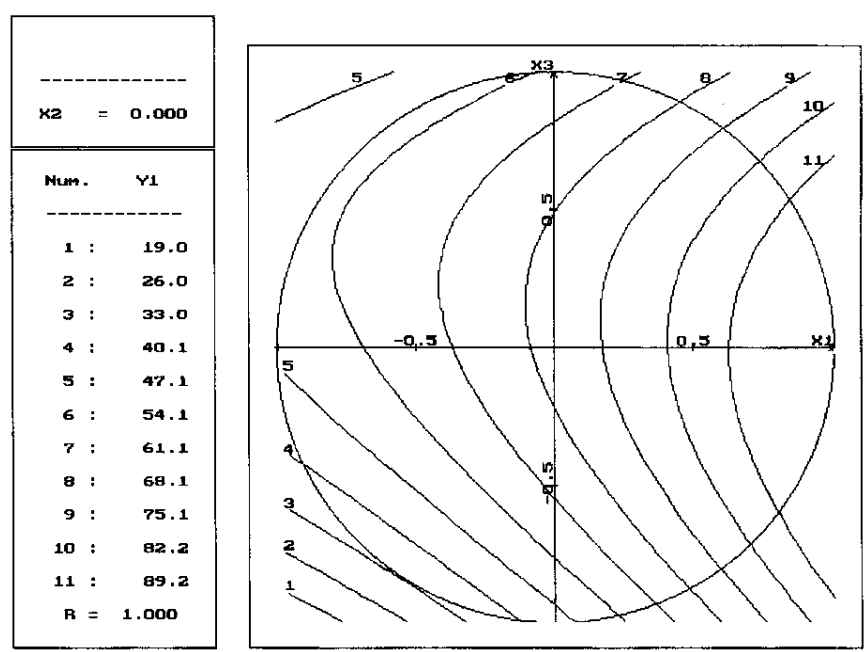

Fig. 6. Optimization of dichloromethane degradation: Variation of the degradation yield according to reaction temperature $\left(X_{1}\right)$ and reaction time $\left(X_{3}\right)$. 
Table VIII. Results of the catalytic oxidation of organochlorines.

\begin{tabular}{|c|c|c|c|c|c|c|c|c|c|}
\hline \multirow[t]{2}{*}{ Substrate } & \multirow{2}{*}{$\begin{array}{c}T \\
\left({ }^{\circ} \mathrm{C}\right)\end{array}$} & \multirow{2}{*}{$\begin{array}{c}{[S]} \\
\left(g L^{-1}\right)\end{array}$} & \multirow{2}{*}{$\begin{array}{l}\text { Reaction } \\
\text { time(min) }\end{array}$} & \multicolumn{2}{|c|}{ Without catalysis } & \multicolumn{2}{|c|}{ With $C u^{2+}$} & \multicolumn{2}{|c|}{ With $\mathrm{LaCoO}_{3}$} \\
\hline & & & & $\Delta S$ & $\triangle T O C$ & $\Delta S$ & $\triangle T O C$ & $\Delta S$ & $\triangle T O C$ \\
\hline PCE & 200 & 5 & 30 & $88 \%$ & $69 \%$ & $94 \%$ & $89 \%$ & $97 \%$ & $90 \%$ \\
\hline PCE & 300 & 5 & 30 & $100 \%$ & $89 \%$ & $100 \%$ & $96 \%$ & - & - \\
\hline TCE & 300 & 20 & 30 & $98 \%$ & $89 \%$ & $99 \%$ & $96 \%$ & $99 \%$ & $87 \%$ \\
\hline TCA & 200 & 5 & 30 & $100 \%$ & $62 \%$ & $97 \%$ & $71 \%$ & $100 \%$ & $63 \%$ \\
\hline DCM & 260 & 6 & 40 & $99 \%$ & $59 \%$ & $94 \%$ & $86 \%$ & $95 \%$ & $69 \%$ \\
\hline
\end{tabular}

(coil, glove finger, agitator, and liquid phase sampling tube) and so the cupric ion concentration decreases considerably. These observations imply a complex oxidation and reduction that affect the different ionic species in solution and the reactor steel. Indeed, the $\mathrm{Cu}^{2+} / \mathrm{Cu}$ couple has an electrochemical potential higher than most of the other metals; Thereby, $\mathrm{Cu}^{2+}$ ion can react with chromium, which is one of the constituent elements of the Hastelloy C276 screwtop with a deposit of copper and an oxidation of chromium. Variable quantities of $\mathrm{Cr}_{2} \mathrm{O}_{7}^{2-}$ have been detected in final effluents $\left(\leq 600 \mu \mathrm{g} \mathrm{L}^{-1}\right)$. The oxidoreduction reaction that affects these metallic species is as follows:

$$
\mathrm{Cu}^{2+}+2 \mathrm{Cr}+5 / 2 \mathrm{O}_{2} 2 \mathrm{H}_{2} \mathrm{O} \rightarrow \mathrm{Cu}+\mathrm{CrO}_{7}^{2-}+4 \mathrm{H}^{+} .
$$

Moreover, the presence of oxygen in the reaction medium favors the oxidation of cupric ions with formation of various oxides. A mixture of these oxides constitutes the precipitate found in the final effluents.

The X-ray diffraction analysis of the lanthanide oxide at the end of the reaction shows the presence of lanthanum oxycarbonate and other metallic oxides, which implies that the perovskites does not resist the operative conditions.

\section{Discussion and mechanisms of degradation}

The organochlorines present a variable resistance to the hydrothermal oxidation. In similar conditions, perchloroethylene and dichloromethane give a lesser TOC yield than trichloroethylene and 1,1,1 trichloroethane. The comparison of tests conducted at the same temperature $\left(200{ }^{\circ} \mathrm{C}\right)$ shows an oxidation yield of the initial substrate superior to $98 \%$ in the case of trichloroethane and trichloroethylene while we observed that it was only $88 \%$ for perchloroethylene.

The degradation of all the compounds is intimately connected to the predominant influence of the reaction temperature. The reaction time and the initial volume of the solution contribute to improve the yield. The positive effect of the reaction time can be interpreted by the fact that the lengthening of the reaction time allows the degradation of the refractory compound formed.

The initial volume of the solution intervenes in the mass transfer and the oxygen dissolution phenomenon. In fact, the total volume of the reactor vessel is constant. The heating of the liquid phase brings about the vaporization of the water so that the thermodynamic equilibrium between liquid water and its vapor phase is satisfied. This equilibrium depends on the heating temperature and the volume of the liquid phase. The more the initial quantity of water is important, the more the vapor phase volume is reduced, so as that a small quan- tity of water is vaporized. A large water volume improves great oxygen dissolution for the oxidation process.

The only factor that has a negative effect on the degradation yield is the substrate concentration. This limitation of the efficiency can be explained by the production of higher quantities of refractory intermediates, which are more or less easily oxidizables.

The characterization of the different organic intermediates formed allows us to make predictions on reaction mechanisms that take place in the degradation of the compounds. All the substrates studied produce methanol and in some cases formic acid. The trichloroethane produces dichloromethane, contrary to perchloroethylene and trichloroethylene. In general, it is admitted a free radical mechanism with formation of hydroperoxydes. The reaction starts with the attack of molecular oxygen on the most vulnerable $\mathrm{C}=\mathrm{H}$ bonds of the organic substrate [23]. This is followed by dechlorination steps that liberate the chlorine in the $\mathrm{Cl}^{-}$form. The necessary energy for this attack is provided by the heating of the reaction medium. The higher the temperature of the medium, the more energy is available. The catalysts allow to reach rapidly the threshold necessary for the beginning of the reaction at lower temperatures.

The following schematic pathways can be proposed for each of the compounds studied:

Dichloromethane:

$$
\begin{aligned}
& \mathrm{CH}_{2} \mathrm{Cl}_{2}+\mathrm{O}_{2} \rightarrow \mathrm{CHCl}_{2}-\mathrm{O}-\mathrm{OH} \\
& \mathrm{CHCl}_{2}-\mathrm{O}-\mathrm{OH} \rightarrow \mathrm{CHCl}_{2}-\mathrm{O}^{\circ}+\mathrm{OH}^{\circ} \\
& \mathrm{CHCl}_{2}-\mathrm{O}-\mathrm{OH} \rightarrow \mathrm{HCOOH}+2 \mathrm{Cl}^{-} \\
& \mathrm{CHCl}_{2}-\mathrm{O}^{\circ}+\mathrm{H}_{2} \mathrm{O} \rightarrow \mathrm{CH}_{2} \mathrm{OHCl}+\mathrm{OH}^{\circ}+\mathrm{Cl}^{-} \\
& \mathrm{CH}_{2} \mathrm{OHCl}+\mathrm{H}_{2} \mathrm{O} \rightarrow \mathrm{CH}_{3} \mathrm{OH}+\mathrm{OH}^{\circ}+\mathrm{Cl}^{-} \\
& \mathrm{HCOOH}+2 \mathrm{Cl}^{-} \rightarrow \mathrm{CO}_{2}+2 \mathrm{HCl} \\
& \mathrm{CH}_{3} \mathrm{OH}+\mathrm{O}_{2} \rightarrow \mathrm{HCOOH}+\mathrm{H}_{2} \mathrm{O} \\
& \mathrm{HCOOH}+1 / 2 \mathrm{O}_{2} \rightarrow \mathrm{CO}_{2}+\mathrm{H}_{2} \mathrm{O}
\end{aligned}
$$

\section{1,1,1 Trichloroethane:}

$$
\begin{aligned}
& \mathrm{H}_{3} \mathrm{C}-\mathrm{CCl}_{3}+\mathrm{O}_{2} \rightarrow \mathrm{CCl}_{3}-\mathrm{CH}_{2}-\mathrm{O}-\mathrm{OH} \\
& \mathrm{CCl}_{3}-\mathrm{CH}_{2}-\mathrm{O}-\mathrm{OH} \rightarrow \mathrm{CCl}_{3}-\mathrm{CH}_{2}-\mathrm{O}^{\circ}+\mathrm{OH}^{\circ} \\
& \mathrm{CCl}_{3}-\mathrm{CH}_{2}-\mathrm{O}-\mathrm{OH} \rightarrow \mathrm{CO}_{2}+\mathrm{CH}_{2} \mathrm{Cl}_{2}+\mathrm{HCl} \\
& \mathrm{CCl}_{3}-\mathrm{CH}_{2}-\mathrm{O}-\mathrm{OH}+\mathrm{O}_{2} \rightarrow 2 \mathrm{CO}_{2}+3 \mathrm{HCl} \\
& \mathrm{CCl}_{3}-\mathrm{CH}_{2}-\mathrm{O}-\mathrm{OH}+2 \mathrm{H}_{2} \mathrm{O} \rightarrow \mathrm{HCOOH}+\mathrm{CH}_{3} \mathrm{OH}+3 \mathrm{Cl}^{-} \\
& \mathrm{CCl}_{3}-\mathrm{CH}_{2}-\mathrm{O}^{\circ}+\mathrm{H}_{2} \mathrm{O} \rightarrow \mathrm{CH}_{2} \mathrm{OH}-\mathrm{CCl}_{3}+\mathrm{OH}^{\circ}
\end{aligned}
$$




$$
\begin{aligned}
& \mathrm{H}_{3} \mathrm{C}-\mathrm{CCl}_{3}+\mathrm{OH}^{\circ} \rightarrow \mathrm{CH}_{2} \mathrm{OH}-\mathrm{CCl}_{3} \\
& \mathrm{CH}_{2} \mathrm{OH}-\mathrm{CCl}_{3}+2 \mathrm{H}_{2} \mathrm{O} \rightarrow \mathrm{CH}_{3} \mathrm{OH}+\mathrm{CO}_{2}+3 \mathrm{HCl} \\
& \mathrm{CH}_{3} \mathrm{OH}+\mathrm{O}_{2} \rightarrow \mathrm{HCOOH}+\mathrm{H}_{2} \mathrm{O} .
\end{aligned}
$$

Formic acid and dichloromethane formed in this way undergo the same reactions as mentioned before.

The trichloroethylene and the perchloroethylene follow a different mechanism because of the double $\mathrm{C}=\mathrm{C}$ bonds characteristic of their structure.

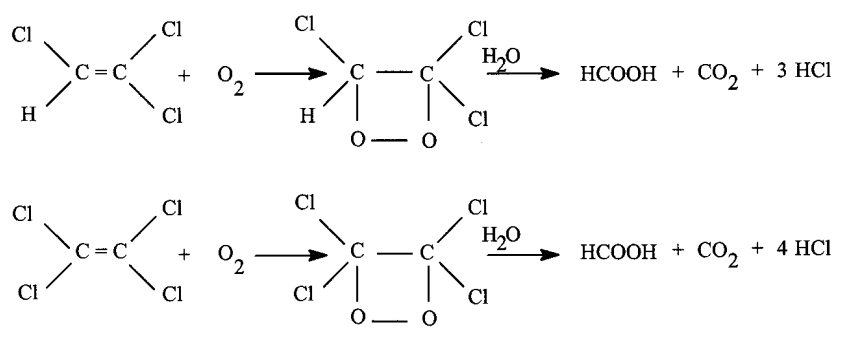

The presence of a $\mathrm{C}-\mathrm{H}$ bond in the structure of the trichloroethylene makes easier the initiation of the reaction than in the case of the perchloroethylene. We observed that other mechanisms could equally intervene to produce methanol in small quantity.

\section{Conclusion}

The results obtained allows to conclude that the Hydrothermal Oxidation Process can be applied to the detoxification of the effluents containing organochlorines. The degradation of these compounds produces very variable yields according to operative conditions. The best yield was obtained at high reaction temperatures, a relatively low substrate concentration and a reaction time of about 30 minutes.

The main refractory organic intermediates formed are methanol and formic acid. Methanol is more resistant to a temperature increase than formic acid, which disappears above $300{ }^{\circ} \mathrm{C}$. The chlorine liberated during the degradation is transformed into hydrochloric acid.

The catalysis permits a significant improvement of the degradation yield. The $\mathrm{Cu}^{2+}$ ion gives better results than $\mathrm{LaCoO}_{3}$ and $\mathrm{V}_{2} \mathrm{O}_{5}$. The major drawback for this, is the difficulty to recover the catalyst at the end of the reaction. Moreover, the catalysis by $\mathrm{Cu}^{2+}$ brings about other oxydoreduction reactions leading to the formation of various oxides. It is supposed that in reality, the homogeneous catalysis becomes coupled to a heterogeneous catalysis due to the oxides formed.
The study of catalysis phenomena during the hydrothermal oxidation will permit a better choice of catalysts that could yield the best possible results while at the same time minimizing undesirable effects.

\section{References}

1. Antonini, G.; Gislais, P. (Technique et Documentation Lavoisier Paris 1995).

2. Schaefer, Ph. T. Environ. Management 1981, 100-104.

3. Mishra, V. S.; Mahajani, V. V.; Joshi J. B. Ind. Eng. Chem. Res. 1995, 34, 2-48.

4. Hao, O. J.; Phull, K.K.; Chen, J. M.; Davis,A. P. J. Hazardous Mat. 1993, 3451-3468.

5. Copa, W. M.; Randall; T. L. Zimpro Passavant; Rothschild, W, I (1990).

6. Wilks, J. P.; Holt, N. S. Waste Manag. 1990, 10(3), 197-203.

7. Holman, D. J. Radioactive Waste Management 2. BNES, London, 1989.

8. Kalman, J.; Palùai; Gy.; Szebényi, I. Int. Conf. Budapest, 1987.

9. Chowdury, A. K.; Copa, W. C. Indian Chemical Engineer, Vol. XXIII N³ CH44-51. July-September, 1986.

10. Rappe, G. C. Environ. Prog. 1985, 4(1), 56-60.

11. Dietrich, M. J.; Randall, T. L.; Canney, P. J. Environ. Prog. 1985, 4(3), 174-7.

12. Hao, O. J.; Phull, K. K. Environ. Science Technol. 1993, 27, 1650-1658.

13. Shende, R. V.; Mahajani, V. V. Indian J. Tech. 1995, 2, 129136.

14. Sorensen, E.; Bjerre, A. B. Waste Management 1992, 12, 349354.

15. Willms, R. S.; Balinsky, A. M.; Reible, D. D.; Wetzel, D. M.; Harrison, D. P. Ind. Eng. Res. 1987, 26, 148-154.

16. Roeck, D. R.; Anderson, P. H. 79th Annual Meeting OF the Air Pollution Control Association, Minneapolis, Minnesota June 22-27, 1986.

17. Pessik, A. Thesis, Université d'Aix-Marseille III, 1995, pp 123-125.

18. Perrin, R.; Scharff, J. P. Chimie Industrielle Tome 1 Masson, Paris, 1993; pp 259-316.

19. Goupy, J. La méthode des Plans d'expériences Dunod Bordas, Paris 1988.

20. Mathieu, D.; Phan-Tan-Luu, R. Logiciel NEMROD, version 2.0. Laboratoire de prospective réactionnelle et d'analyse de l'information, Université d'Aix-Maresille III, 1994.

21. Levec, J.; Pintar, A. Chem. Eng. Science 1992, 47(9-11), 23952400.

22. Imamura, S.; Sakai, T. J. Japan Petrol. Inst. 1980, 25(2), 7480.

23. Jouffert, M. Recueil des Conférences. Lyon Ecully 18-12, Mai 1978. 